\title{
INFLUENCE OF COBALT CHROMIUM FRAMEWORK FABRICATION TECHNIQUES ON MARGINAL ACCURACY AND FRACTURE BEHAVIOR OF IMPLANT-SUPPORTED METAL CERAMIC BRIDGES
}

\author{
Hanaa I. Sallam*
}

\begin{abstract}
Statement of problem: Marginal fit and structural integrity are keys for long term success of implant supported restorations. Little information is available regarding precision of marginal adaptation and fracture behavior of implant supported metal ceramic bridges with recently introduced milled Cobalt Chromium frameworks.

Aim of the study: Evaluation of marginal accuracy (before and after porcelain application) and fracture resistance of implant supported metal ceramic bridges with Cobalt Chromium (Co-Cr) frameworks fabricated using the new computer aided designing /computer aided manufacturing (CAD/CAM, soft milling/post sintering) technique in comparison to the conventional casting technique.
\end{abstract}

Materials \& Methods: A total of 10 epoxy resin models were constructed into which two titanium dummy implants were inserted in each model and received straight titanium abutments. 10 Co-Cr cement retained frameworks were fabricated on the implant models, 5 with the new CAD/ CAM soft milling/ post sintering technique (group I) and the other 5 with the lost wax casting technique (group II). All frameworks were veneered with porcelain by the layering technique. Vertical marginal gap distance between the $\mathrm{Co}-\mathrm{Cr}$ frameworks and the implant abutments was measured using a stereo microscope at 16 predetermined points/abutment before and after porcelain application. Then metal ceramic bridges were cemented onto their corresponding abutments with temporary resin cement. Samples were loaded compressively under static vertical load till fracture in a universal testing machine with a loadcell of $5 \mathrm{kN}$ at a cross-head speed of $1 \mathrm{~mm} / \mathrm{min}$. The load required to fracture was recorded in Newton. Fracture modes of all samples were visually analyzed. Data were statistically analyzed using the repeated measures ANOVA test for vertical marginal gap distance results $(\mathrm{P}<0.05)$ and the students $t$ - test for fracture resistance results $(\mathrm{P}<0.05)$.

Results: Framework fabrication techniques as well as porcelain application was statistically insignificantly affecting the vertical marginal gap distance as indicated by the repeated measures ANOVA test $(\mathrm{P}>0.05)$. Bridges with $\mathrm{CAD} / \mathrm{CAM}$ fabricated frameworks recorded

\footnotetext{
* Associate Professor of Fixed Prosthodontics, Faculty of Oral and Dental Medicine, Cairo University.
} 
the lowest statistically insignificant vertical marginal gap distance mean value before porcelain application $(24.63 \pm 4.27 \mu)$, while those with cast frameworks recorded the highest statistically insignificant vertical marginal gap distance mean value after porcelain application $(25.21 \pm 7.08 \mu)$. Implant supported metal ceramic bridges with cast frameworks showed higher fracture resistance mean value $(1608.56 \pm 215.04 \mathrm{~N})$ than those with CAD/CAM fabricated frameworks $(1392.73 \pm 160.75 \mathrm{~N})$, the difference between groups was statistically insignificant as indicated by Student's t -test $(\mathrm{P}>0.05)$.

Conclusions: $\mathrm{CAD} / \mathrm{CAM}$ soft milled/post sintered $\mathrm{Co}-\mathrm{Cr}$ frameworks may be considered promising alternative to conventional cast frameworks for implant supported metal ceramic bridges in terms of marginal accuracy and fracture resistance.

KEY WORDS: Implant-supported bridges, Co-Cr,CAD/CAM, Soft milling/post sintering, Lost wax casting, Marginal Accuracy, Fracture Resistance

\section{INTRODUCTION}

Patients with edentulous or partially dentate jaws can be restored predictably with different types of implant-supported fixed dental prostheses. ${ }^{(1)}$ Although most of the concentration today is on allceramic restorations, metal ceramic restorations, whether they are tooth supported or implant supported, are still considered as the gold standard because of theirexcellentbiocompatibility,consistent esthetics,superior strength and marginal adaptation. (2) The production of the metallic framework in the dental laboratory has been carried out using the lost wax casting technique. ${ }^{(3)}$ Although the alloys of choice were gold-based when the casting technique was first developed, they were gradually replaced by base-metal alloys such as nickel-chromium (Ni$\mathrm{Cr})$ and cobalt-chromium $(\mathrm{Co}-\mathrm{Cr}){ }^{(4)} \mathrm{Ni}-\mathrm{Cr}$ alloys may cause allergic reactions, therefore, $\mathrm{Co}-\mathrm{Cr}$ ones are the most common base-metal alternative for patients known to be allergic to nickel . Co-Cr alloys are increasingly used because of their low cost compared to noble alloys, biocompatibility, high strength, high modulus of elasticity and high corrosion resistance. However, their high melting range, making it difficult to manipulate in the dental laboratory . Additionally, their high hardness and low ductility make them difficult to finish and polish. ${ }^{(4)}$
$\mathrm{Co}-\mathrm{Cr}$ restorations are traditionally fabricated by the conventional lost wax casting technique. The many steps in this technique increase the number of variables that can cause discrepancies in the final restoration. ${ }^{(3-5)}$ The CAD/CAM technologies have revolutionized the $\mathrm{Co}-\mathrm{Cr}$ restorations production either by subtractive or additive manufacturing. ${ }^{(5-11)}$ $\mathrm{CAD} / \mathrm{CAM}$ hard milling is one of the subtractive processes for producing $\mathrm{Co}-\mathrm{Cr}$ restorations ${ }^{(5-7,9-11)}$, the formation of casting-induced flaws and porosities are minimized by using $\mathrm{Co}-\mathrm{Cr}$ alloy blanks manufactured under standardized industrial conditions. However, increased tool and machine wear caused by the high rigidity of the "solid" blank and high maintenance costs are the main disadvantages of the technique .

Additive manufacturing assisted by $\mathrm{CAD} / \mathrm{CAM}$ technology as selective laser melting (SLM) is an alternative method for producing $\mathrm{Co}-\mathrm{Cr}$ restorations directly from a three-dimensional CAD model by fusing fine layers of metal powder using a highpower focused laser beam. (5-7,10,11) However, this method currently requires very expensive equipment and is, thus, restricted to large $\mathrm{CAD} /$ CAM centers in the dental industry. Another recent approach in the production of $\mathrm{Co}-\mathrm{Cr}$ dental restorations is dry milling of "soft" Co-Cr blanks, in which the alloy powder is finely distributed in a 
binder material that is capable of burn-out, thereby reducing manufacturing time and costs. The milled restoration is subsequently sintered to full density in a special, high-temperature sintering furnace under an argon protective gas atmosphere. ${ }^{(8,11)}$

Framework materials and fabrication techniques affected the vertical marginal fit of implant supported restorations as mentioned by many authors. ${ }^{(12-14)}$ Faot et al ${ }^{(12)}$ favored the use of $\mathrm{Co}-\mathrm{Cr}$ alloy for construction of implant superstructures as it exhibited the best cervical and occlusal fit among the groups of alloys tested.

From the clinical point of view, one of the factors affecting the long term success of implant supported restoration is being passively fitted to the underlying abutments. The passive fit concept in cement-retained implant supported restorations has been defined as the simultaneous contact around the circumference of all the abutments over their respective implants, and that of the prosthesis over their respective abutments. ${ }^{(15)}$ Poorly fitting implant frameworks can potentially result in pain and sensitivity, loosening of screw joints, fatigue fractures of components (the metallic structure or the aesthetic veneering) and peri-implant marginal bone loss. ${ }^{(16)}$

A group of authors compared the vertical fit of CAD/CAM fabricated implant supported $\mathrm{Co}-\mathrm{Cr}$ and zirconia frameworks to that of conventionally fabricated frameworks and concluded that $\mathrm{CAD} /$ CAM fabricated frameworks exhibited better fit compared with the conventionally fabricated ones. ${ }^{(17)}$ Few contradicting results were found in the literature concerning the marginal and internal adaptation of $\mathrm{Co}-\mathrm{Cr}$ frameworks fabricated by the recent techniques, two studies found that direct laser metal sintering group showed the best fit among the tested groups (milling and casting). ${ }^{(7,10)}$ In contrast, Nesse et $\mathrm{al}^{(5)}$ reported that the milled $\mathrm{Co}-\mathrm{Cr}$ group showed the best overall fit followed by the cast one, while the selective laser melting method had the poorest fit. Additionally, Kocaağaoğlu et $\mathrm{al}^{(11)}$ reported that metal ceramic restorations produced with hard and soft milling techniques exhibited better marginal adaptations than those produced by laser sintering or casting.

The fit of metal ceramic restorations not only depends on the accuracy of the production method but also on the subsequent fabrication procedures. ${ }^{(18)}$ Several studies have reported that the porcelain firing stages affect the fit of the $\mathrm{Co}-\mathrm{Cr}$ restorations. ${ }^{(11,19-21)}$

Another crucial factors for the long term success of implant supported metal ceramic restoration are their mechanical resistance and structural integrity in the oral cavity. ${ }^{(2)}$ The mechanical response of the functionally loaded metal ceramic restoration is dependent on the mechanical properties of the supporting metal core which rely on material composition and production method. Results from in vitro study carried out by Suliman and Steyern ${ }^{(22)}$ showed that there is no difference in fracture strength of metal ceramic restorations with copings fabricated from $\mathrm{Co}-\mathrm{Cr}$ using different production technologies (casting, milling and laser sintering). Similarly, Krug et $\mathrm{al}^{(8)}$ reported that cast and CAD/CAM milled and sintered metal ceramic bridges were comparable in their fracture performance. Moreover, adhesion of the veneering porcelain to the underlying metal substructure is essential for their clinical durability. ${ }^{(22)}$ Implant supported metal ceramic fixed partial dentures suffer from ceramic veneer fracture at a rate of $6.7 \% .^{(23)}$

With respect to the material, it is not known to which extent these soft milled and sintered $\mathrm{Co}-\mathrm{Cr}$ frameworks, whether individual or in combination with veneering porcelain, are equivalent to frameworks that are cast according to conventional lost wax technique. Therefore, the purpose of this study was to evaluate the marginal accuracy (before and after porcelain application) and fracture resistance of implant supported metal 
ceramic bridges with $\mathrm{Co}-\mathrm{Cr}$ frameworks fabricated using CAD/CAM (soft milling/post sintering) technique in comparison to the conventional casting technique. The first null hypothesis was that no differences would be found in marginal adaptation of implant supported metal ceramic bridges with $\mathrm{CAD} / \mathrm{CAM}$ or cast $\mathrm{Co}-\mathrm{Cr}$ frameworks. The second null hypothesis was that application of veneering porcelain would not affect the marginal adaptation of implant supported metal ceramic bridges. The third null hypothesis was that no differences would be found in fracture resistance of implant supported metal ceramic bridges with CAD/CAM or cast CoCr frameworks.

\section{MATERIALS AND METHODS}

\section{Implant models fabrication}

A split copper mold $(2 \times 3 \times 6 \mathrm{~cm})$ was machine milled and used for construction of ten epoxy resin models (Kemapoxy 150, CMB International, Egypt). Each epoxy resin model received two internal connection titanium dummy implants (Legacy 1 system,Implant direct,Sybron International, USA) with $3.7 \mathrm{~mm} \times 13 \mathrm{~mm}$ and $4.7 \mathrm{~mm} \times 13 \mathrm{~mm}$ dimensions for the premolar and molar, respectively with an interimplant distance of $14 \mathrm{~mm}{ }^{(13)}$ from center to center to simulate a clinical condition of missing mandibular first molar and the second premolar and the second molar were the abutments. Drilling of the implant sites in the epoxy resin models was carried out by the aid of a paralleling device and the corresponding drills then implants were luted to their sites with cyanoacrylate adhesive (Superglue; Pacer Technology, Rancho, Cucamonga, CA).

Two straight titanium abutments (Legasy system, Implant direct, Sybron International, USA.) with $6^{\circ}$ taper, $0.5 \mathrm{~mm}$ chamfer finish line, $5.5 \mathrm{~mm}$ length and $3.5 \mathrm{~mm}$ diameter for the premolar \& $4.5 \mathrm{~mm}$ for the molar were screwed to the implants in each model by titanium screws which were torqued to $30 \mathrm{Ncm}$ following the manufacturer recommendations using calibrated torque wrench and hex tool of the implant system. The abutments screw holes were sealed with cotton pellets and temporary filling material (Cavit,3M ESPE,USA).

\section{Fabrication of the implant supported metal ce- ramic bridges}

Ten standardized cement retained implant supported mandibular 3 units fixed-fixed metal ceramic bridges were fabricated in this study. The 10 bridges were classified into two groups according to their $\mathrm{Co}-\mathrm{Cr}$ framework fabrication techniques; group I ( $n=5)$ :frameworks fabricated with the $\mathrm{CAD} /$ CAM soft milling/ post sintering technique and group II $(n=5)$ : frameworks fabricated with the lost wax casting technique.

\section{A) Fabrication of the Co-Cr frameworks:}

\section{a) Frameworks fabrication by CAD/CAM technology}

Standardized frameworks were fabricated by the CAD/CAM soft milling/post sintering technique according to the following steps:

Optical impression of the implant models (group I): The five epoxy resin models with their corresponding abutments were sprayed with titanium dioxide powder (Cerec. Optispray, Sirona Dental Systems GmbH, Bensheim, Germany)then scanned by In Eos scanner (Sirona Dental Systems $\mathrm{GmbH}$, Bensheim, Germany) and the resultant 3D images of the models were saved on the computer.

Virtual designing of the metal frameworks: By the aid of the in Lab 4.3 CAD software (Sirona Dental Systems GmbH, Bensheim, Germany), frameworks were individually designed onto their corresponding virtual 3D models with $0.5 \mathrm{~mm}$ thickness $^{(7,11,21)}$ and $30 \mathrm{~m} \mu$ cement space ${ }^{(11)}$. This design was enlarged by $8.5 \%$ to compensate for the Co - Cr sintering shrinkage. 
Frameworks milling: A Co-Cr blank specific for the soft milling procedure (Copra Sintec K, White peaks Dental Solutions $\mathrm{GmbH} \&$ Co. KG, Germany/Chemical composition: Co balance, $\mathrm{Cr}$ $26,5-30 \%$, Mo 4,5 - 7\%, Mn $0-1 \%$, Si $0-1 \%$, $\mathrm{Fe} 0-1 \%, \mathrm{C} 0-0.35$, other $<1 \%$ ) with $98 \times 16 \mathrm{~mm}$ dimensions was used in this study. The in Lab 15 CAM software was used for the milling procedure which was carried out in the in Lab MC x 5 milling machine following the dry milling protocol (Sirona Dental Systems GmbH, Bensheim, Germany).

Frameworks sintering: After completion of the milling procedure, the frameworks were sintered in a high temperature sintering furnace (in Fire HTC speed, Sirona Dental Systems GmbH, Bensheim, Germany) under Argon protective atmosphere for 5 hours at $1280^{\circ} \mathrm{C}$ with one hour holding time at the sintering temperature using the special sintering tray and its cover as well as sintering bell as recommended by the manufacturer.

\section{b) Frameworks fabrication by lost wax casting technique}

Five frameworks were fabricated by conventional casting technique (group II) as one piece casting. In order to standardize their shape and thickness, all wax patterns were fabricated by the CAD/CAM technology. Epoxy resin models of group II were scanned as mentioned before and the wax patterns were designed similar to the $\mathrm{CAD} / \mathrm{CAM}$ fabricated frameworks but without the $8.5 \%$ enlargement. Using the in Lab 15 CAM software, wax patterns were milled from a wax blank (Copra wax, $98 \times 16 \mathrm{~mm}$, White peaks Dental Solutions GmbH \& Co. KG, Germany) using the in Lab MC x5 milling machine. The milled wax patterns were seated on their corresponding abutments and margins were checked under magnification loupes with a power of $2.5 \times$ (Task Vision, NJ) .

Milled wax patterns were coated with surfactant (Aurofilm, Bego, Germany), and allowed to dry for
3 minutes then invested (Bellavest SH \& begosal mixing liquid,Bego, $160 \mathrm{~g}$. powder / $29 \mathrm{ml}$ liquid). For wax elimination, the investment rings were placed in an oven (Midtherm $200 \mathrm{MP}$; Bego) and temperature was increased from room temperature until $900^{\circ} \mathrm{C}$ and held for 60 minutes. After wax elimination, the Co-Cr alloy (Kera C, Eisenbacher Dentalwaren ED GmbH, Germany/Chemical composition: Co $60 \%, \mathrm{Cr} 24,5 \%$, W $9 \%, \mathrm{Nb} 2 \%$, V $2 \%$, Mo $1.1 \%$, Fe $0.15 \%$, Si $0.9 \%$ Others < 0.1 ) was cast in an induction casting machine (Fornax 35 HF induction casting machine, $10060 \mathrm{~S}$. Secondodi Pinerolo- Italy) at the manufacturer recommended casting temperature $\left(1485^{\circ} \mathrm{C}\right)$. The investment was removed by airborne particle abrasion with $250 \mu$ aluminum oxide in a sandblaster (Duoster F1 -BEGO) at 5-7 bar pressure and sprues were cut by carbide disks at low speed. Metal frameworks were ultrasonically cleaned in distilled water .

All metal frameworks were checked for any defect or incompleteness then seated onto their corresponding abutments and the margins were evaluated using a dental explorer (Hu-Friedy Chicago, IL) and magnification loupes with a power of $2.5 \times$.

Two Co-Cr disc shape samples (10 mm diameter $\times 0.5 \mathrm{~mm}$ thickness) were fabricated one by the CAD/CAM technology and the other by casting for scanning electron microscopic analysis (Quanta FEG 250 Environmental Scanning Electron Microscope, Netherlands).

\section{B) Porcelain veneering of the $\mathrm{Co}-\mathrm{Cr}$ frameworks}

In order to standardize the thickness and shape of the veneering porcelain for all frameworks and by the aid of the CAD/CAM technology, an anatomical full contour 3 unit fixed-fixed bridge was designed on the 3D virtual image of the scanned abutments (previously used for the designing of the metal framework) then split this design into framework and veneering layers. The designed veneering layer was milled from wax 
(Coprawax,98×16mm, White peaks Dental Solutions $\mathrm{GmbH} \&$ Co. KG, Germany) using the in Lab MC $x 5$ milling machine. Then, the milled wax was seated on the CAD/CAM fabricated metal framework on the epoxy resin model . Polyvinyl siloxane putty impression material (Elite, Zhermack S.p.A., Italy) was used to fabricate a silicon index on the milled wax. After setting of the impression material,the index was removed and sectioned mesio-distally and used to check the veneering porcelain layer of all metal frameworks.

Prior to their porcelain veneering, the $\mathrm{Co}-\mathrm{Cr}$ frameworks were subjected to sandblasting with $110 \mu$ aluminum oxide particles for the CAD/CAM ones and with $125 \mu$ aluminum oxide particles for the cast frameworks at 3 bar pressure and $20 \mathrm{~mm}$ distance between the nozzle and the sample surface following the manufacturer recommendations. All frameworks were ultrasonically cleaned in distilled water for five minutes and dried by oil free air spray.

Epoxy resin models with their abutments were used to hold and support the metal frameworks during the porcelain build up procedure which was carried out by the layering technique using feldspathic porcelain (VITA VMK Master, Vita Zahnfabrik, Germany). Opaque porcelain was first applied to the metal framework and fired at $\left(950^{\circ} \mathrm{C}\right)$ in a porcelain furnace (Programat P310 furnace, Ivoclar Vivadent,Schaan, Liechtenstein), followed by dentin and enamel porcelain application and firing $\left(930^{\circ} \mathrm{C}\right)$ then autoglaze firing $\left(920^{\circ} \mathrm{C}\right)$. Porcelain was applied, condensed and fired according to the manufacturer's recommendations. The finished metal ceramic bridges were placed onto their corresponding abutments and the margins were evaluated using a dental explorer and magnification loupes with a power of $2.5 \times$.

\section{Cementation of the bridges}

A specially fabricated cementing device was used to standardize the cementation procedure for all samples. An automix temporary resin cement (Sensitemp resin, Sultan, Hackensack, NJ, USA) was applied to the fitting surface of each bridge retainers and the bridge was immediately seated onto its corresponding abutments under finger pressure then placed in the cementing device under constant axial load of $5 \mathrm{Kg}$. ${ }^{(24)}$ Excess cement at the margins was removed by a dental explorer. The cementation procedure was repeated till cementation of all bridges and the cemented bridges were stored in $100 \%$ humidity at $37^{\circ} \mathrm{C}$ for 24 hours.

\section{Testing of the samples}

\section{A) Vertical marginal gap distance measurements}

Vertical marginal gap distance measurements were carried out for each metal frameworks before porcelain veneering at 16 predetermined reference points around the titanium abutment for the premolar (4 points/surface) and 16 for the molar ${ }^{(13)}$. The measurements were repeated again at the same reference points after porcelain veneering without cementation of the bridges to the underlying abutments.

Each framework was secured on its abutments on the epoxy resin model by the aid of a specially constructed sample seating device in order to avoid displacement or seating errors during measurements. The vertical marginal gap distance between the margin of each retainer and the titanium abutment was assessed using stereo microscope (Olympus, SZ-PT Japan) at an original magnification $\mathrm{x} 40$. Photographs of the margin were taken and the image was recorded with a digital camera (ADP 10-Olympus Corp, Tokyo, Japan) fitted on the microscope. The images were exported to a computer and analyzed with an image processing program. For each bridge, the vertical marginal gap distance value was the mean gap of all measurements around the premolar and molar abutments.

\section{B) Fracture Resistance testing}

All samples were individually mounted on a computer controlled materials testing machine (Model 3345; Instron Industrial Products, Norwood, 
MA, USA) with a loadcell of $5 \mathrm{kN}$ and data were recorded using computer software (Instron ${ }^{\circledR}$ Bluehill Lite Software). Each epoxy resin model with its cemented metal ceramic bridge was secured to the lower compartment of the testing machine and compressive static vertical load was applied at the middle of the occlusal surface of pontic by a metallic rod with spherical tip (5.8 $\mathrm{mm}$ diameter) attached to the upper movable compartment of testing machine and traveling at a cross-head speed of $1 \mathrm{~mm} / \mathrm{min}$.A tin foil sheet with $1 \mathrm{~mm}$ thickness was placed inbetween the pontic and the load applicator to achieve homogenous stress distribution and minimize the transmission of local force peaks. The load at failure was recorded in Newton using computer software (Instron ${ }^{\circledR}$ Bluehill Lite Software) .

Fractured samples were visually examined by naked eye and by magnification loupes with a power of $2.5 \times$ to analyze their fracture modes .

\section{Statistical analysis}

Repeated measures ANOVA test was used to study the effect of the Co-Cr framework fabrication technique, porcelain application and their interactions on mean vertical marginal gap distance.
The significance level was set at $\mathrm{P}<0.05$.

Students t- test was used to study the effect of the $\mathrm{Co}-\mathrm{Cr}$ framework fabrication technique on mean fracture resistance. The significance level was set at $\mathrm{P}<0.05$.

Statistical analysis was performed with IBM (IBM Corporation, NY, USA) SPSS Statistics Version 20 for Windows (SPSS, Inc., IBM Company).

\section{RESULTS}

\section{Statistical Analysis Results}

\section{A) Vertical Marginal Gap Distance Results}

The means, standard deviations (SD) and 95\% Confidence interval $(95 \% \mathrm{CI})$ for the mean values of the vertical marginal gap distance measured in $(\mu \mathrm{m})$ of implant supported metal ceramic bridges as functions of framework fabrication techniques and porcelain application were summarized in Table (1) and graphically represented in Figure (1). Framework fabrication techniques as well as porcelain application was statistically insignificantly affecting the vertical marginal gap distance as indicated by the repeated measures ANOVA test $(\mathrm{P}>0.05)$.

TABLE (1) Comparison of vertical marginal gap distance results (Mean \pm SD) \& $(95 \%$ CI) for implant supported metal ceramic bridges as functions of framework fabrication techniques and porcelain application

\begin{tabular}{|c|c|c|c|c|c|c|c|c|c|}
\hline \multirow{3}{*}{$\begin{array}{l}\text { Framework Fabrication } \\
\text { techniques } \\
\text { Application }\end{array}$} & \multicolumn{4}{|c|}{$\mathrm{CAD} / \mathrm{CAM}$} & \multicolumn{4}{|c|}{ Conventional Casting } & \multirow{3}{*}{$\begin{array}{l}\text { P value (for } \\
\text { the effect of } \\
\text { fabrication } \\
\text { technique) }\end{array}$} \\
\hline & \multirow[t]{2}{*}{ Mean } & \multirow[t]{2}{*}{ SD } & \multicolumn{2}{|c|}{$\begin{array}{l}\text { Confidence } \\
\text { intervals }\end{array}$} & \multirow[t]{2}{*}{ Mean } & \multirow[t]{2}{*}{ SD } & \multicolumn{2}{|c|}{$\begin{array}{l}\text { Confidence } \\
\text { intervals }\end{array}$} & \\
\hline & & & Lower & Upper & & & Lower & Upper & \\
\hline Before & 24.63 & 4.27 & 19.80 & 43.07 & 25.03 & 4.87 & 19.52 & 43.13 & $0.845 \mathrm{~ns}$ \\
\hline After & 24.98 & 10.23 & 13.40 & 36.50 & 25.21 & 7.08 & 17.20 & 40.79 & $0.9519 \mathrm{~ns}$ \\
\hline $\begin{array}{l}\mathrm{P} \text { value (for the effect of } \\
\text { porcelain application) }\end{array}$ & $\mathrm{P}$ value & $0.9187 \mathrm{~ns}$ & & & $P$ value & $0.9390 \mathrm{~ns}$ & & & \\
\hline
\end{tabular}

Significant $(p<0.05) \quad n s ;$ non-significant $(p>0.05)$ 


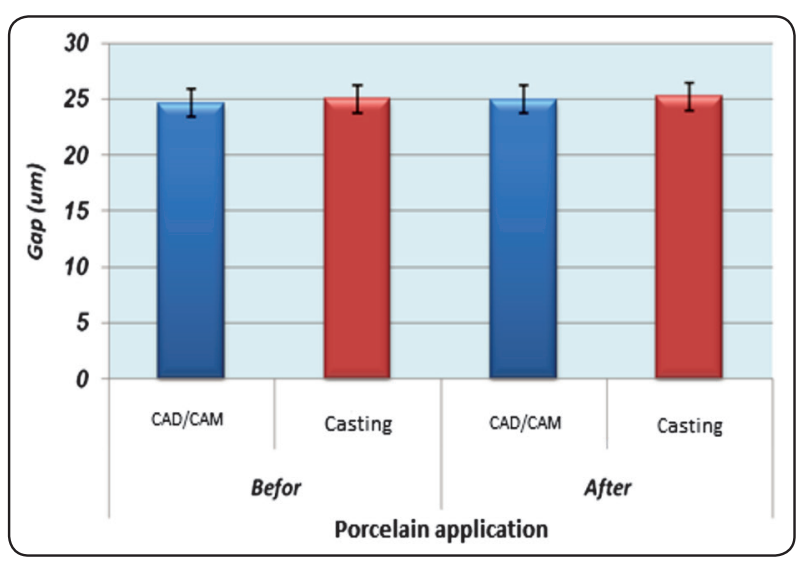

Fig. (1) A column chart comparing vertical marginal gap distance results (Mean $\pm \mathrm{SD}$ ) of implant supported metal ceramic bridges as functions of framework fabrication techniques and porcelain application.

\section{Regarding the effect of framework fabrication} techniques; before porcelain application, CAD/ CAM fabricated frameworks recorded lower statistically insignificant vertical marginal gap distance mean value $(24.63 \pm 4.27 \mu)$ than those fabricated by the conventional casting technique $(25.03 \pm 4.87 \mu)$ as indicated by repeated measures ANOVA test $(\mathrm{P}=0.845)$. Similar results pattern was recorded for frameworks after porcelain application,where $\mathrm{CAD} / \mathrm{CAM}$ and cast frameworks recorded $(24.98 \pm 10.23 \mu)$ and $(25.21 \pm 7.08 \mu)$, respectively as indicated by repeated measures ANOVA test $(\mathrm{P}=0.9519)$

Concerning the effect of porcelain application; in the CAD/CAM group, frameworks recorded lower statistically insignificant vertical marginal gap distance mean value $(24.63 \pm 4.27 \mu)$, before porcelain application than after $(24.98 \pm 10.23 \mu)$ as indicated by repeated measures ANOVA test $(\mathrm{P}=0.9187)$. Similar results pattern was recorded for frameworks fabricated by the conventional casting technique, where before and after porcelain application, frameworks recorded $(25.03 \pm 4.87 \mu)$ and $(25.21 \pm 7.08 \mu)$, respectively as indicated by repeated measures ANOVA test $(\mathrm{P}=0.9390)$.

Interaction between variables showed that $\mathrm{CAD} /$ CAM fabricated frameworks before porcelain application recorded the lowest vertical marginal gap distance mean value $(24.63 \pm 4.27 \mu)$, while cast frameworks after porcelain application recorded the highest marginal gap distance mean value $(25.21 \pm 7.08 \mu)$.

\section{B. Fracture Resistance Results}

The means, standard deviations (SD) and (95\% CI) for the mean values of the fracture resistance of implant supported metal ceramic bridges as a function of framework fabrication techniques were summarized in Table (2) and graphically represented in Figure (2). Framework fabrication techniques was statistically insignificantly affecting the fracture resistance as indicated by the students $\mathrm{t}$ - test $(\mathrm{P}>0.05)$.

Results showed that implant supported metal ceramic bridges with frameworks fabricated by the conventional casting technique recorded higher fracture resistance mean value $(1608.56 \pm 215.04 \mathrm{~N})$ than those with CAD/CAM fabricated frameworks $(1392.73 \pm 160.75 \mathrm{~N})$. The difference between groups was statistically insignificant as indicated by t-test $(\mathrm{t}=1.798, \mathrm{p}=0.110>0.05)$.

TABLE (2) Comparison of fracture resistance results (Mean \pm SD) \& (95\% CI) of implant supported metal ceramic bridges as a function of framework fabrication technique.

\begin{tabular}{|c|c|c|c|c|}
\hline \multirow{2}{*}{ Framework Fabrication Technique } & \multirow{2}{*}{ Mean \pm SD } & \multicolumn{2}{|c|}{ Confidence intervals } & Statistics \\
\cline { 3 - 5 } & & Lower & Upper & t-test \\
\hline CAD/CAM & $1392.73 \pm 160.75$ & 1193.2 & 1592.3 & P value \\
\hline Conventional Casting & $1608.56 \pm 215.04$ & 1341.6 & 1875.5 & $\mathbf{0 . 1 1 0}$ ns \\
\hline
\end{tabular}

Significant $(p<0.05) \quad n s ;$ non-significant $(p>0.05)$ 


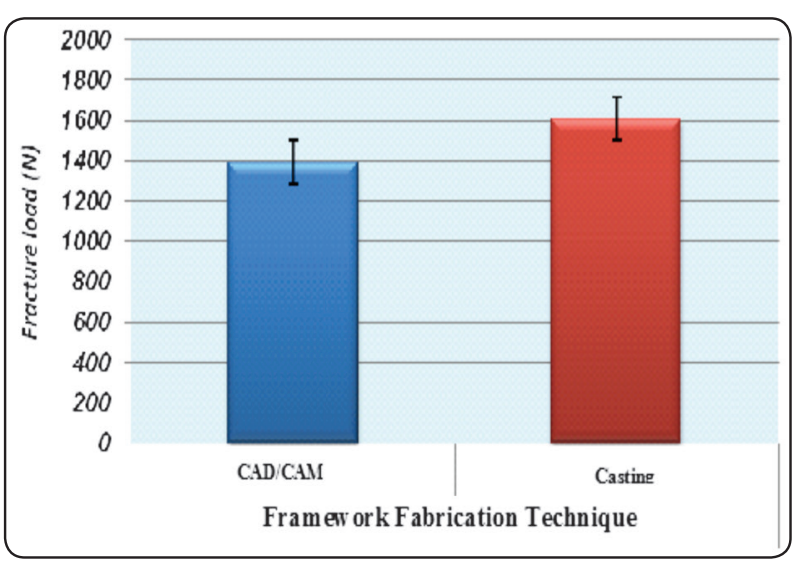

Fig. (2) A column chart comparing the fracture resistance mean values of implant supported metal ceramic bridges with $\mathrm{CAD} / \mathrm{CAM}$ and cast frameworks.

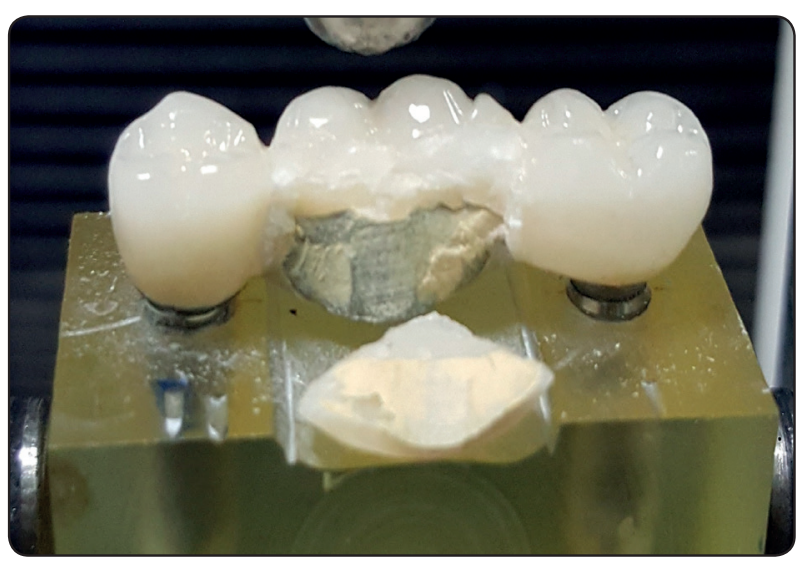

Fig. (3) Fractured implant supported metal ceramic bridges with CAD/CAM fabricated frameworks showed cohesive fracture within the porcelain

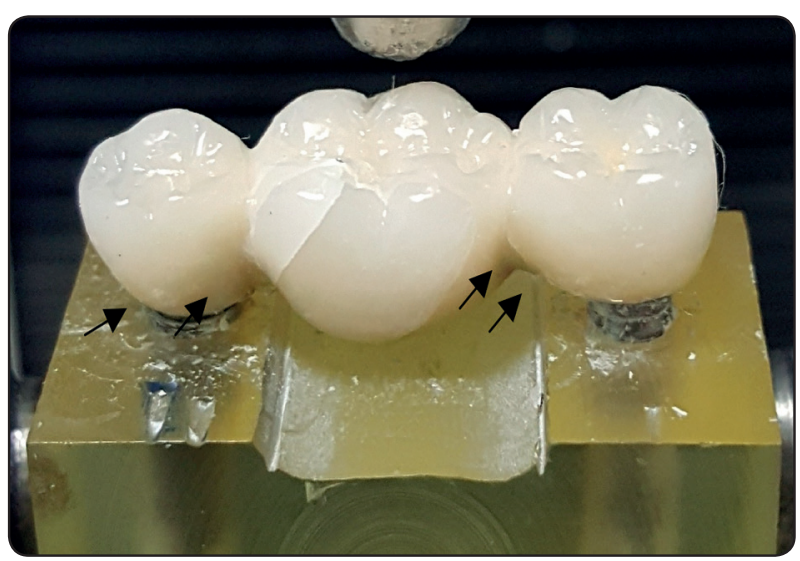

Fig. (4) Fractured implant supported metal ceramic bridges with cast frameworks showed visible cracks in the pontic and microcracks at the cervical margins of the bridge retainers

\section{Fracture Mode Results}

\section{a. Implant supported metal ceramic bridges with CAD/CAM fabricated frameworks}

All bridges showed cohesive type of fracture within the porcelain layers, a thin layer of opaque porcelain remains attached to metal surface and the bulk of it remains attached to the dentin porcelain layer. In smaller areas, the opaque was completely detached from the dentin porcelain. The fracture was located at the pontic area, extending transversely and occlusally from the dentin porcelain at the connector area distal to the premolar to the connector area mesial to the molar which showed less destruction. Microcracks were radiated from the connector area toward the adjacent axial surface. (Figure 3)

\section{b. Implant supported metal ceramic bridges with cast frameworks}

All bridges showed visible cracks in the axial surface of the pontic and in the connector areas where several microcracks were extended cervically. Also microcracks were observed at the cervical margins of the bridge retainers(black arrows ). (Figure 4)

\section{DISCUSSION}

Metal ceramic systems are still popular because ceramic systems present several strength limitations, Sghaireen (25) reported that metalceramic restorations supported by titanium abutments were more resistant to fracture than all-ceramic restorations supported by zirconia abutments. Teigen and Jokstad ${ }^{(1)}$ in 2012 suggested that it is time to consider $\mathrm{Co}-\mathrm{Cr}$ as the first choice of metal alloy for fabricating the framework for implant supported fixed prostheses.

A CAD/ CAM metallic restoration production process was recently introduced with the development of special metal blanks that consist of a Co-Cr alloy powder, which is finely distributed in a binder material that is capable of burn-out and 
from which the work pieces are cut while soft until a subsequent sintering process occurs to accomplish densification. This process does not exhibit the typical disadvantages of a hard milling subtractive process and can be extensively applied in ordinary dental laboratories using available CAD/CAM equipment. ${ }^{(8)}$ Because of the speed up production and cost effective, CAD/CAM soft milling /post sintering technique can be used as an alternative to the traditional casting technique.(6)

The Co-Cr soft milling/post sintering alloys can be categorized as tough and highly ductile,thus, the restorations fabricated from them could be effectively burnished. ${ }^{(4,26)}$

Implant supported cement retained metal ceramic bridges were fabricated in this study as they offer many advantages due to the absence the of the occlusal access hole, the use of less expensive components and restorative procedures. Additionally, they have higher fracture resistance than screw retained and screw-cement retained restorations as reported by many authors. ${ }^{(27,28)}$ The main disadvantage of cement retained restorations is the difficulty of their retrievability which can be solved by the use of temporary luting agents for the cementation procedure. Therefore, all bridges in this study were luted to their abutments using temporary cement similar to other studies. ${ }^{(14,27)}$

In this research, to minimize variations inherent to any manual process, the wax patterns for frameworks fabricated by the casting procedure were constructed by the CAD/CAM technology similar to other researches how found that $\mathrm{Co}-\mathrm{Cr}$ frameworks obtained from milled wax patterns had better marginal and internal fit than those obtained from manually fabricated wax patterns..$^{(7,10)}$

Misfiting implant cemented restorations can lead to biomechanical failure, components fracture or even bone loss. ${ }^{(2,16)}$ Studies evaluating the marginal adaptation of fixed restorations on teeth or implants suggest different methods of measuring marginal discrepancy between the restoration margins and abutment tooth or implant abutment. Of these, the direct microscopic, sectioning and replica methods were mostly preferred..$^{(5,7,10-13,17,19,21)}$ The direct microscopic method is easier, faster, and can be easily repeated, although the precision of the measurements is lower. Conversely, the sectioning method demonstrates the marginal discrepancy more clearly. ${ }^{(29)}$ In the present study, the direct microscopic method was chosen to evaluate the vertical marginal gap distance before and after porcelain application. The sectioning technique was not used because it is destructive and would have prevented the evaluation of the effect of veneering porcelain .

Vertical marginal gap distance measurements were carried out in this study without cementation of the frameworks to the abutments as it was previously documented in the literature that cementation procedure contributed to higher marginal discrepancy. ${ }^{(21)}$

Regarding the effect of the framework fabrication technique on the vertical marginal gap distance,the results of this study support the acceptance of the first null hypothesis which stated that no differences would be found in marginal adaptation of implant supported metal ceramic bridges with $\mathrm{CAD} / \mathrm{CAM}$ or cast $\mathrm{Co}-\mathrm{Cr}$ frameworks. Before and after porcelain application,the $\mathrm{CAD} / \mathrm{CAM}$ frameworks registered lower mean vertical marginal gap distance than the cast ones,although these differences were statistically insignificant (Table 1). These results may be attributed to the quality of the milled wax patterns used in the casting technique ${ }^{(7,10)}$. The results were consistent with those of Gunsoy and Ulusoy ${ }^{(10)}$ who found insignificant difference in the marginal and internal fit between $\mathrm{Co}-\mathrm{Cr}$ restorations fabricated by the milled wax with lost wax method and the milled $\mathrm{Co}-\mathrm{Cr}$ ones. In the present study, the milled frameworks registered lower mean marginal gap values than the cast one similar to many studies. ${ }^{(5,11,17)}$ These lower values may be 
attributed to the CAD/CAM technology which resulted in restorations with improved adaptation due to the fewer production steps compared to the conventional casting technique and due to the precision of the scanner that reads the abutments, and the software that transform the scanning data into 3D model in the computer and the precision of the milling machine that will CAM the object from the CAD data. ${ }^{(7)}$

On the other hand, the results of this study contradicting those of Zaghloul and Younis (13) who found that implant supported cast frameworks had better marginal fit than those fabricated by the CAD/CAM technology. These contradictions may be referred to methodological differences as they compared the cast metal frameworks with the CAD/ CAM zirconia frameworks. Also the results were not in agreement with those of Örtorp ${ }^{(7)}$ et al who declared that $\mathrm{Co}-\mathrm{Cr}$ three unit fixed prostheses fabricated by the milled wax with lost wax casting technique had better fit than those fabricated by the milling technique, and this difference may be resulted from the difference in the milling technique followed as they used the hard milling technology.

In light of results obtained, the second null hypothesis which stated that application of veneering porcelain would not affect the marginal adaptation of implant supported metal ceramic bridges was accepted .Insignificant difference in vertical marginal gap distance was found between frameworks before and after porcelain application for both types of frameworks tested in the study (Table 1). This results may be attributed to the high sag resistance of the Co-Cr alloy, ${ }^{(4)}$ and due to absence of the oxidation cycle prior to porcelain application (not recommended by the manufacturer) as the greatest amount of distortion during the simulated porcelain firings took place during this cycle. ${ }^{(19)}$ This result was in agreement with that of Tiossi et al. ${ }^{(30)}$ who compared titanium and $\mathrm{Co}-\mathrm{Cr}$ frameworks in three-unit implant retained FDPs before and after simulated porcelain firings and reported insignificant differences. Controversy, Svanborg et al ${ }^{(20)}$ found that ceramic veneering resulted in minor improvement of the fit for Co$\mathrm{Cr}$ full arch implant supported frameworks, the difference in the results may be attributed to the difference in the restoration type as they used full arch $\mathrm{Co}-\mathrm{Cr}$ and $\mathrm{CNC}$ milled Ti frameworks. On the other hand, Kaleli and Saraç ${ }^{(21)}$ reported that marginal discrepancy increased after porcelain application for metal ceramic restorations with $\mathrm{Co}-\mathrm{Cr}$ frameworks prepared by different methods. The difference with this study may be related to the different $\mathrm{Co}-\mathrm{Cr}$ fabrication techniques tested.

In this research, implant supported metal ceramic bridges with $\mathrm{CAD} / \mathrm{CAM}$ or cast $\mathrm{Co}-\mathrm{Cr}$ frameworks exhibited insignificant differences concerning their fracture resistance (Table 2) this led to acceptance of the third null hypothesis. The results were in accordance with those of Krug et $\mathrm{al}^{(8)}$ who found insignificant difference in the fracture behavior of metal-ceramic bridges with frameworks from cobalt-chromium alloy manufactured using conventional casting or (CAD/CAM) milling and sintering technique. Similarly, the results were in agreement with those of many authors ${ }^{(22)}$ who compared the fracture strength of porcelain fused to metal restorations made of cast, milled or laser sintered $\mathrm{Co}-\mathrm{Cr}$ and concluded that insignificant difference was found between the restorations produced by the different technologies.

Despite the fact that there was insignificant difference between the fracture resistance of implant supported metal ceramic bridges with $\mathrm{CAD} /$ $\mathrm{CAM}$ or cast $\mathrm{Co}-\mathrm{Cr}$ frameworks, there are still numerical differences that deserve to be discussed. Fracture resistance of the metal ceramic restoration is dependent on the mechanical properties of the supporting metal core. These properties and microstructures are greatly dependant on the manufacturing technique as well as the chemical 
composition. ${ }^{(6,31)}$ The two Co -Cr alloys used in this study for the two different fabrication techniques do not have exactly the same chemical compositions. The properties of the alloy may be affected not only by the principal elements but also by the minor alloying elements. ${ }^{(4)}$ They also differ in their microstructure as showen in their SEM analysis pictures; the cast $\mathrm{CO}-\mathrm{Cr}$ disc showed dendritic structure that is typical of cast alloys with minimum porosity $^{(8)}$ (Figure 5). Conversly, the microstructure of the soft milled / post sintered Co-Cr disc exhibited a larger grain size with homogenous and completely isolated microporosity,which is typical for the free sintering process ${ }^{(8)}$ (Figure 6).

Regarding the fracture mode results, all bridges in this study showed fracture or cracking of the veneered porcelain (Figure $3 \& 4$ ). It has been demonstrated that implant supported metal ceramic restorations are more susceptible to porcelain veneer fracture than tooth supported restorations due to absence of the periodontal ligaments around the implants which lead to lack of proprioceptive mechanism. In addition to loss of shock absorbing feature in the ankylosed implants bone interface. ${ }^{(15)}$ This ankylosed clinical condition was simulated in the present study by the adhesive luting of the implants to their holes in the epoxy resin models.

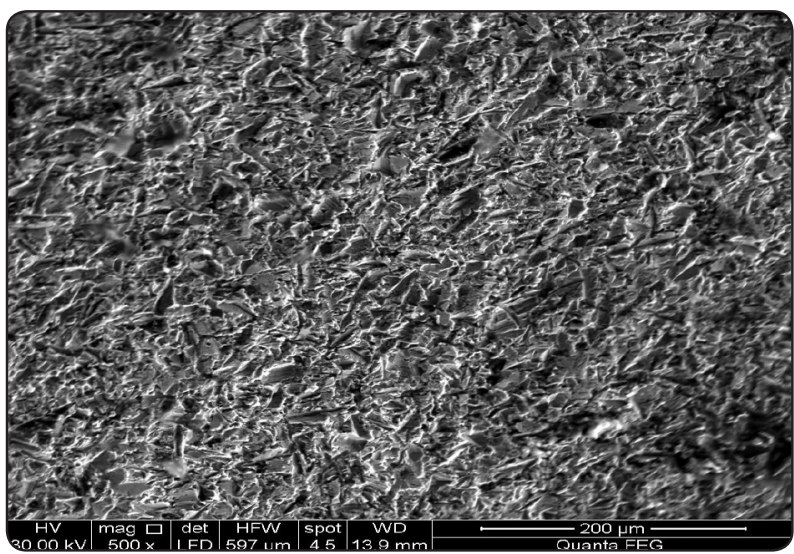

Fig. (5) SEM figure of Co-Cr alloy fabricated by casting procedure at $500 \times$
In the present research, bridges with $\mathrm{CAD} /$ CAM fabricated frameworks showed cohesive fracture within the opaque porcelain, where a very thin layer of the opaque porcelain remains attached to the underlying metal framework. The junction of metal framework and veneering porcelain can be considered one of the weakest links in metal ceramic restorations and constantly experiencing overload and consequently, may fail. ${ }^{(23)}$ This fracture mode did not occur with bridges with cast frameworks. The chemical composition of the alloys can be one of the factors that influences the bond strength in the metal ceramic restorations. ${ }^{(32)}$ The material composition vary between the two alloys used which might be an influencing factor on the results in this study. Additionally, the sandblasting procedure of the metal frameworks prior to porcelain application differed in the two groups because the manufacturer's recommendations varied between the different materials. The grain size of the aluminum oxide particles used for the sandblasting procedure varied as it was $110 \mu$ for the CAD/CAM frameworks and $125 \mu$ for the cast framework and this might be affected the fracture mode results.

Implant supported metal ceramic bridges with cast frameworks showed different fracture mode where the stronger cast frameworks (as indicated from its fracture resistance values (1608.56 \pm 215.04$)$ properly supported the overlying porcelain which

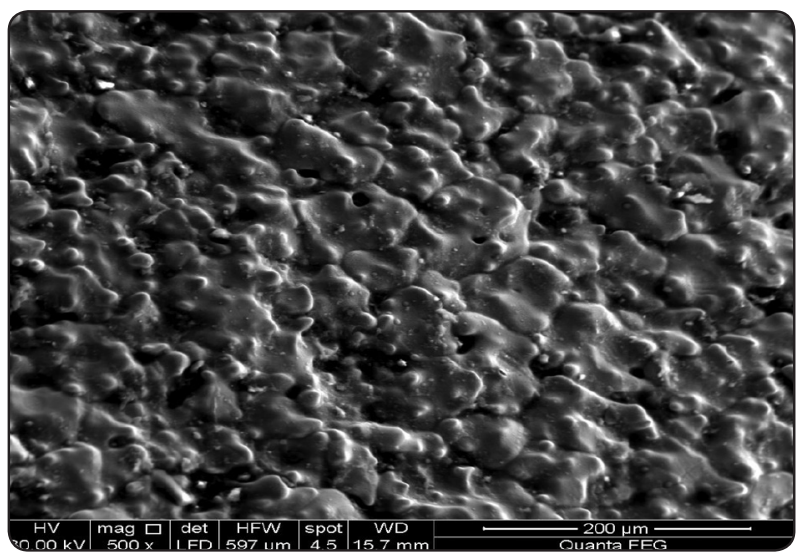

Fig. (6) SEM figure of Co-Cr alloy fabricated by CAD/CAM procedure at $500 \times$ 
only showed visible cracks and microcracks without actual fractures. The porcelain veneering process itself might have resulted in microcrack formation at the cervical margins of the bridge retainers as mentioned earlier in the literature by many authors who also stated that cementation of implant supported restorations led to a general increase in the number of detectable microcracks. ${ }^{(33)}$

The marginal gap values of samples fabricated by new CAD/CAM technology were clinically acceptable ${ }^{(34)}$, furthermore, their fracture resistance results were higher than the normal masticatory forces applied on the premolar and molar teeth. ${ }^{(35-37)}$ Consequently, the new $\mathrm{Co}-\mathrm{Cr}$ fabrication technique (CAD/CAM soft milling/post sintering) is considered successful in terms of marginal accuracy and fracture resistance.

A possible limitations of this study may be related to the small number of samples and in vitro setting. A 3 -dimensional marginal discrepancy evaluation was not performed and only vertical marginal gap distance was measured similar to many researches..$^{(5,7,11,13,21)}$ Samples were subjected to fracture under static loading instead of dynamic one which more resembling the clinical environment. Clinical trials would be meaningful to assess periimplant health and the fracture behavior of implant supported metal ceramic bridges with different CoCr frameworks.

\section{CONCLUSIONS}

Within the limitations of this in-vitro study, CAD/ CAM soft milled/post sintered $\mathrm{Co}$ - $\mathrm{Cr}$ frameworks may be considered promising alternative to conventional cast frameworks for implant supported metal ceramic bridges in terms of marginal accuracy and fracture resistance.

\section{REFRENCES}

1. Teigen K, Jokstad A. Dental implant superstructures using Cobalt-Chromium alloy compared with gold alloy framework veneered with ceramic or acrylic resin:a retrospec- tive cohort study up to 18 years. Clin Oral Impl Res. 2012; 23:853-860.

2. Shadid R M, Sadaqah N R, Naba L A, Omari W M. Porcelain fracture of metal-ceramic tooth-supported and implant-supported restorations: A review. Ojst.3013;3:411418.

3. Shillingburg H, Sather D, Wilson E, Cain J, Mitchell D, Blanco L and Kesseler J. Fundamentals of Fixed Prosthodontics. $4^{\text {th }}$ ed .Quintessence, 2012; pp: 447-469.

4. Sakaguchi, R.L.; Powers, J.M. Craig's Restorative Dental Materials, $13^{\text {th }}$ ed.; Elsevier Mosby: Philadelphia, PA, USA, 2012; pp. 199-251.

5. Nesse H, Ulstein D M A, Vaage M M, Øilo M .Internal and marginal fit of cobalt-chromium fixed dental prostheses fabricated with 3 different techniques. J Prosthet Dent. 2015; 114(5): 686-692.

6- Kim H R, Jang S, Kim Y K, Son J S, Min B K, Kim K-H, Kwo T-Y. Microstructures and Mechanical Properties of Co-Cr Dental Alloys Fabricated by Three CAD/CAMBased Processing Techniques. Materials 2016, 9 (7), 596; doi:10.3390/ma9070596.

7. Örtorp A, Jönsson D, Mouhsen A, Steyern P V .The fit of cobalt-chromium three-unit fixed dental prostheses fabricated with four different techniques: A comparative in vitro study. Dent Mater. 2011; 27,(4): 356-363.

8. Krug K-P, Knauber A W, Nothdurft F P. Fracture behavior of metal-ceramic fixed dental prostheses with frameworks from cast or a newly developed sintered cobalt-chromium alloy. Clin Oral Invest.2015; 19(2): 401-411

9. Kane LM, Chronaios D, Sierraalta M, George FM. Marginal and internal adaptation of milled cobalt-chromium copings. J Prosthet Dent. 2015;114(5):680-685.

10. Gunsoy S, Ulusoy M. Evaluation of marginal/internal fit of chrome-cobalt crowns: Direct laser metal sintering versus computer-aided design and computer-aided manufacturing. Niger J Clin Pract. 2016;19(5):636-644.

11. Kocaağaoğlu H, Kılınç Hİ, Albayrak H, Kara M .In vitro evaluation of marginal, axial, and occlusal discrepancies in metal ceramic restorations produced with new technologies. J Prosthet Dent.2016;116(3)368-374.

12. Faot F, Suzuki D, Senna PM, da Silva WJ, de Mattias Sartori IA. Discrepancies in marginal and internal fits for different metal and alumina infrastructures cemented on implant abutments. Eur J Oral Sci. 2015;123(3):215-219. 
13. Zaghloul HH, Younis JF. Marginal fit of implant-supported all-ceramic zirconia frameworks. J Oral Implantol. 2013;39(4):417-424.

14. Oyagüe RC, Turrión AS, Toledano M, Monticelli F, Osorio $\mathrm{R}$. In vitro vertical misfit evaluation of cast frameworks for cement-retained implant-supported partial prostheses . J Dent. 2009;37(1):52-8.

15. Misch C E. Dental implant prosthetics .Elsevier, Mosby. Inc., St Louis, 2015;pp.414-451,18-31.

16. Adell R, Lekholm U, Rockler B, Brånemark PI.A 15-year study of osseointegrated implants in the treatment of the edentulous jaw. Int J Oral Surg. . 1981;10(6):387-416.

17. de França DG, Morais MH, das Neves FD, Barbosa GA. Influence of CAD/CAM on the fit accuracy of implantsupported zirconia and cobalt-chromium fixed dental prostheses. J Prosthet Dent. 2015;113(1):22-28.

18. Nawafleh NA, Mack F, Evans J, Mackay J, Hatamleh MM. Accuracy and reliability of methods to measure marginal adaptation of crowns and FDPs: a literature review. J Prosthodont. 2013;22(5):419-428.

19. Zeroas P J, Papazoglou E, Beck F M, Caw A B. Distortion of Three-Unit Implant Frameworks During Casting; Soldering, and Simulated Porcelain Firings. J Prosthod 1999;8:171-179.

20. Svanborg P, Stenport V, Eliasson A. Fit of cobalt-chromium implant frameworks before and after ceramic veneering in comparison with CNC-milled titanium frameworks. CEDR.2015;1(2):49-56.

21. Kaleli N, Saraç D. Influence of porcelain firing and cementation on the marginal adaptation of metal ceramic restorations prepared by different methods . J Prosthet Dent.2016 doi.org/10.1016/j.prosdent.2016.08.016

22. Suleiman S H, Steyern P V V. Fracture strength of porcelain fused to metal crowns made of cast, milled or laser-sintered cobalt-chromium. Acta Odontol Scand.2013; 71(5): 1280-1289

23. Linkevicius T, Vladimirovas E, Grybauskas S, Puisys A, Rutkunas V. Veneer fracture in implant-supported metal-ceramic restorations. Part I: Overall success rate and impact of occlusal guidance. Stomatologija. Bdmj. 2008;10(4):133-139.

24. Zortuk M, Bolpaca P, Kilic K, Ozdemir E, Aguloglu S. Effects of Finger Pressure Applied By Dentists during Cementation of All-ceramic crowns. Eur J Dent 2010;4: 383-388.

25. Sghaireen MG. Fracture resistance and mode of failure of ceramic versus titanium implant abutments and single implant-single implant-supported restorations. Clin Implant Dent Relat Res. 2015;17(3):554-561.
26. Mc Cabe, J.F.; Walls, A.W.G. Applied Dental Materials, $9^{\text {th }}$ ed.; Blackwell Publishing Ltd.: Oxford, UK, 2008; pp. 71-79

27. Zarone F, Sorrentino R, Traini T, Di lorio D, Caputi S. Fracture resistance of implant-supported screw- versus cementretained porcelain fused to metal single crowns: SEM fractographic analysis. Dent Mater. 2007; 23( 3) : 296-301

28. Al-Omari W, Shadid R, Abu-Naba'a L, El Masoud B. Porcelain fracture resistance of screw-retained, cementretained, and screw-cement-retained implant-supported metal ceramic posterior crowns . Journal of Prosthodont 2010; 19: 263-273

29. Sorensen JA. A standardized method for determination of crown margin fidelity. J Prosthet Dent 1990;64:18-24.

30. Tiossi, R., Rodrigues, R.C., de Mattos, M.G., Ribeiro, R.F. Comparative analysis of the fit of 3-unit implant-supported frameworks cast in nickel-chromium and cobaltchromium alloys and commercially pure titanium after casting, laser welding, and simulated porcelain firings. Int.J.Prosthodont. 2008.;21(2):121-123.

31. Al Jabbari YS, Koutsoukis T, Barmpagadaki X, Zinelis S. Metallurgical and interfacial characterization of PFM CoCr dental alloys fabricated via casting, milling or selective laser melting. Dent Mater. 2014;30(4):e79-88

32. de Melo RM, Travassos AC, Neisser MP. Shear bond strengths of a ceramic system to alternative metal alloys. J Prosthet Dent 2005;93:64-69.

33. Karl M, Graef F, Wichmann M, Beck N. Microfractures in metal-ceramic and all-ceramic implant-supported fixed dental prostheses caused by superstructure fixation. Dent Mater. 2012;31(3):338-345.

34. McLean JW, von Fraunhofer JA. The estimation of cement film thickness by an in vivo technique. Br Dent J.1971;131:107-111.

35. DeLong R, Douglas WH. Development of an artificial oral environment for the testing of dental restoratives: bi-axial force and movement control. J Dent Res. 1983; 62(1): 32-36.

36. Tortopidis D, Lyons MF, Baxendale RH, Gilmour WH. The variability of bite force measurement between sessions, in different positions within the dental arch. J Oral Rehabil. 1998;25(9):681-668.

37. Fontijn-Tekamp F A, Slagter A P, Van Der Bilt A, Van 'T Hof M A, Witter D J, Kalk W, Jansen JA. Biting and chewing in overdentures, full dentures, and natural dentitions. J Dent Res 2000; 79(7): 1519-1524. 